\title{
Slight increase in urinary albumin excretion within the normal range predicts incident hypertension in a community-based Japanese population: the Takahata study
}

\author{
Atsushi Hirayama ${ }^{1}$, Tsuneo Konta ${ }^{1}$, Atsushi Hozawa ${ }^{2}$, Ryo Kawasaki ${ }^{3}$, Tetsu Watanabe ${ }^{1}$, \\ Yoko Shibata $^{1}$, Takamasa Kayama ${ }^{4}$, Akira Fukao ${ }^{3,4}$ and Isao Kubota ${ }^{1,4}$
}

Recent studies have suggested that urine albumin excretion in the high normal range predicts hypertension. However, the relationship between urinary albumin excretion in spot urine and incident hypertension remains unclear in the general Japanese population. To clarify this relationship, we conducted a cohort study in a community-based population of 412 normotensive individuals without diabetes and renal insufficiency and examined the incidence of hypertension using the urinary albumin-tocreatinine ratio (UACR) at baseline. Incident hypertension was defined as new-onset systolic blood pressure $\geqslant 140 \mathrm{~mm} \mathrm{Hg}$ and/ or diastolic blood pressure $\geqslant 90 \mathrm{~mm} \mathrm{Hg}$ and/or the use of anti-hypertensive drugs. During the follow-up period (median, 6.7 years), 133 subjects $(32.3 \%)$ newly developed hypertension. The incidence of hypertension increased with an increase in baseline UACR $\left(20.4 \%\right.$ for UACR $<5 \mathrm{mgg}^{-1}, 34.0 \%$ for $5-9.9 \mathrm{mg} \mathrm{g}^{-1}$ UACR and $40.4 \%$ for $\left.10-29.9 \mathrm{mg} \mathrm{g}^{-1}, P=0.002\right)$. Multivariate logistic regression analysis, after adjustment for possible confounders, showed that UACR 5-9.9 $\mathrm{mgg}^{-1}$ and $10-29.9 \mathrm{mg} \mathrm{g}^{-1}$ were independent risks for incident hypertension compared with UACR $<5 \mathrm{mgg}^{-1}$ (odds ratio (OR) 2.15 , $95 \%$ confidence interval $(\mathrm{Cl}) 1.16-4.10$ and $\mathrm{OR} 2.67,95 \% \mathrm{CI} 1.36-5.38$, respectively). Subgroup analysis revealed that subjects with increased UACR ( $\geqslant 5 \mathrm{mg} \mathrm{g}^{-1}$ ) had a higher risk of incident hypertension than did those with low UACR $\left(<5 \mathrm{mgg}^{-1}\right)$, irrespective of their backgrounds (age, sex, smoking, alcohol consumption, obesity and urinary sodium excretion). In conclusion, this study showed that a slight increase in urinary albumin excretion might predict incident hypertension in a community-based Japanese population.

Hypertension Research (2015) 38, 56-60; doi:10.1038/hr.2014.117; published online 10 July 2014

Keywords: blood pressure; cohort study; urinary albumin

\section{INTRODUCTION}

Hypertension is a major health problem, contributing to increased mortality in both developed and developing countries. It remains a main cause of cardiovascular and cerebrovascular disease. ${ }^{1}$ Excess body weight, alcohol consumption, and sodium intake and low physical activity are important modifiable risk factors in the development of hypertension. ${ }^{2}$ However, the pathophysiology and mechanism underlying the development of hypertension are still unclear.

Chronic kidney disease is recognized as a risk factor for increased mortality, ${ }^{3}$ and albuminuria is an early clinical manifestation of chronic kidney disease. Albuminuria is defined as increased urinary excretion of albumin (urine albumin-to-creatinine ratio (UACR) $\geqslant 30 \mathrm{mgg}^{-1}$ in spot urine). Albuminuria is an independent risk factor for all-cause and cardiovascular mortality in the general population in Japan. ${ }^{4}$

Hypertension is generally thought to induce albuminuria. However, several studies have shown that albuminuria precedes the development of hypertension. ${ }^{5-9}$ Furthermore, studies have shown that a slight increase in urinary albumin excretion, even within the normal range, is associated with a high risk of incident hypertension, mainly in Western populations. ${ }^{6,8}$ However, to our knowledge no study has investigated the association between urine albumin excretion and development of hypertension in East Asian populations, whose genetic background and dietary habits differ from those of Western populations. Therefore, our aim was to clarify

${ }^{1}$ Department of Cardiology, Pulmonology and Nephrology, Yamagata University School of Medicine, Yamagata, Japan; ${ }^{2}$ Department of Preventive Medicine and Epidemiology, Tohoku Medical Megabank Organization, Yamagata, Japan; ${ }^{3}$ Department of Public Health, Yamagata University School of Medicine, Yamagata, Japan and ${ }^{4}$ Global COE, Yamagata University School of Medicine, Yamagata, Japan

Correspondence: Dr T Konta, Department of Cardiology, Pulmonology and Nephrology, Yamagata University School of Medicine, Yamagata 2-2-2, lida-Nishi, Yamagata 990-9585, Japan.

E-mail: kkonta@med.id.yamagata-u.ac.jp

Received 24 September 2013; revised 30 April 2014; accepted 22 May 2014; published online 10 July 2014 
whether a higher level of UACR within the normal range predicts incident hypertension in a community-based population in Japan.

\section{METHODS}

\section{Study population}

The Takahata study recruited adult subjects from a community-based, annual health check-up, to which all inhabitants aged $\geqslant 40$ years in the town of Takahata (Yamagata prefecture, Japan) were invited. The institutional ethics committees of the Yamagata University School of Medicine and the town of Takahata approved this study (24 May 2004, No. 3), and all subjects provided written informed consent. The procedures were performed in accordance with the Helsinki Declaration. Details of the study design, recruitment procedure and profile of the population have been published elsewhere. ${ }^{4}$

We conducted a baseline survey from 2004 to 2006 and a follow-up survey in 2011. Among 1546 subjects who agreed to join the survey at baseline, 99 subjects had missing critical information (that is, blood pressure (BP), blood glucose, estimated glomerular filtration rate and UACR), and 881 subjects were excluded because they had hypertension, diabetes, estimated glomerular filtration rate $\leqslant 60 \mathrm{ml} \mathrm{min}^{-1}$ per $1.73 \mathrm{~m}^{2}$, UACR $\geqslant 30 \mathrm{mg} \mathrm{g}^{-1}$ (albuminuria) or a history of cardiovascular and/or kidney disease at baseline. Therefore, in this analysis, the eligible number of subjects at baseline was 566, and 412 subjects attended the follow-up survey (follow-up rate, $72.8 \%$; median followup period, 6.7 years; Figure 1).

\section{Baseline survey}

At baseline, participants used a self-reported questionnaire to document medical history, current medication, family history, smoking habits (current, past or never) and alcohol consumption. Systolic and diastolic BPs were determined using a mercury monometer with the subject seated for at least $5 \mathrm{~min}$ before the measurement. The measurement was performed twice, and the mean value was used for statistical analyses. Hypertension was defined as systolic BP $\geqslant 140 \mathrm{~mm} \mathrm{Hg}$ and/or diastolic BP $\geqslant 90 \mathrm{~mm} \mathrm{Hg}$ and/or the use of anti-hypertensive medication. Normal BP was defined as systolic BP $<120$ $\mathrm{mmHg}$ and diastolic BP $<80 \mathrm{mmHg}$. Prehypertension was defined as $120 \leqslant$ systolic BP $<140 \mathrm{~mm} \mathrm{Hg}$ and/or $80 \leqslant$ diastolic BP $<90 \mathrm{~mm} \mathrm{Hg}^{2}$ Body mass index (BMI) was calculated using measurements of weight and height. Obesity was defined as BMI $\geqslant 25 \mathrm{~kg} \mathrm{~m}^{-2}$ in both men and women. Plasma glucose was measured using the hexokinase enzymatic reference method. The presence of diabetes was ascertained by the use of hypoglycemic medication and/or fasting plasma glucose $\geqslant 126 \mathrm{mg} \mathrm{dl}^{-1}$ and/or glycosylated hemoglobin (HbAlc) $\geqslant 6.5 \%$ (cut-off values as recommended by the Japan Diabetes Society). Urinary albumin concentration was determined by immunoturbidimetry. UACR was measured in single-spot urine specimens collected before breakfast. Serum creatinine was measured using an enzymatic method, and estimated glomerular filtration rate was obtained using the Japanese equation for estimated glomerular filtration rate. ${ }^{10}$ Twenty-four-hour urinary sodium excretion was estimated in spot urine specimens using Kawasaki's equation. ${ }^{11}$

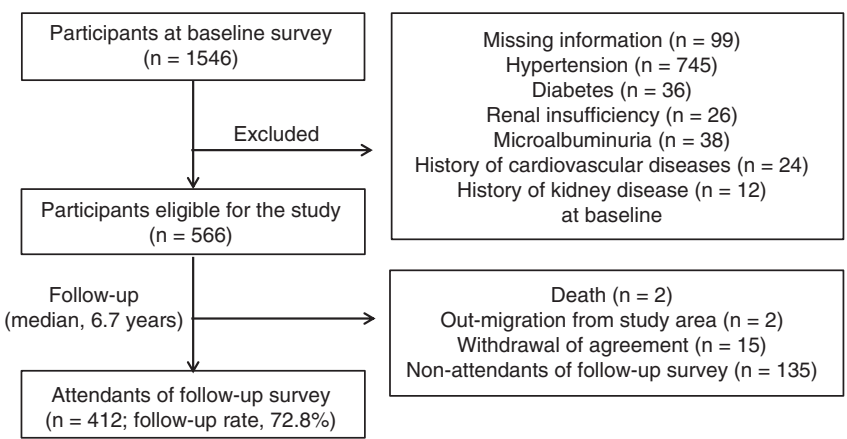

Figure 1 Derivation of the study population.

\section{Follow-up survey}

We conducted the follow-up survey in 2011. BP values were measured in the same manner as at baseline, and information on medication was collected. Incident hypertension was defined as new-onset systolic BP $\geqslant 140 \mathrm{~mm} \mathrm{Hg}$ and/ or diastolic BP $\geqslant 90 \mathrm{~mm} \mathrm{Hg}$ and/or the use of anti-hypertensive medication at follow-up.

\section{Statistical analyses}

We categorized subjects into three groups according to UACR values $(<5,5-$ 9.9 and $\left.10-29.9 \mathrm{mg} \mathrm{g}^{-1}\right) \cdot \chi^{2}$-Tests, analysis of variance and Kruskal-Wallis tests were used to compare baseline characteristics. We performed multivariate logistic regression analyses to estimate the odds ratio and $95 \%$ confidence interval of UACR for incident hypertension, using age, sex, alcohol consumption, smoking status, BMI, 24-h urinary excretion of sodium and HbAlc as confounding factors in Model 1. We then further adjusted for BP categories at baseline (normal BP and prehypertension) in Model 2. Subgroup analyses were performed in subjects divided by age, sex, smoking, obesity, alcohol intake, estimated urinary sodium excretion and BP categories. A significant difference was defined as $P<0.05$. All statistical analyses were performed using JMP version 10.0 software (SAS Institute, Cary, NC, USA).

\section{RESULTS}

\section{Baseline characteristics}

A comparison between 412 attendants and 154 non-attendants at the follow-up survey showed that attendants were older with higher urinary sodium excretion; however, the other characteristics were not significantly different between the two groups (Table 1). During the follow-up period, 133 subjects $(32.3 \%)$ developed hypertension. The baseline characteristics of subjects with incident hypertension and those of normotensive subjects at the follow-up survey are shown in Table 2. Compared to normotensive subjects, those with incident hypertension were older, had higher systolic and diastolic BP, BMI and UACR; a higher proportion were males.

\section{Association between UACR and incident hypertension}

The numbers of subjects with UACR $<5,5-9.9$ and 10 $29.9 \mathrm{mg} \mathrm{gCr}^{-1}$ were 98 (23.8\%), $199(48.3 \%)$ and $115(27.9 \%)$, respectively. The crude incidence rate of hypertension increased with an increase in UACR levels from baseline (20.4, 34.0 and $40.4 \%$ for UACR $<5$, 5-9.9 and 10-29.9 $\mathrm{mgg}^{-1}$, respectively; $P=0.002$ ). Simple logistic regression analysis showed that the increased UACR

Table 1 Comparison of baseline characteristics between attendants and non-attendants at the follow-up survey

\begin{tabular}{|c|c|c|c|}
\hline & Attendants & Non-attendants & P-value \\
\hline Number & 412 & 154 & \\
\hline Age (years) & $56.9 \pm 8.6$ & $55.4 \pm 11.3$ & 0.03 \\
\hline Men (\%) & 39.3 & 36.3 & 0.52 \\
\hline Systolic BP (mm Hg) & $122.0 \pm 11.3$ & $120.3 \pm 12.3$ & 0.15 \\
\hline Diastolic BP (mm Hg) & $73.7 \pm 8.4$ & $73.7 \pm 8.6$ & 0.90 \\
\hline Smoker (\%) & 29.1 & 36.4 & 0.09 \\
\hline Alcohol consumption (\%) & 42.0 & 40.3 & 0.71 \\
\hline Body mass index $\left(\mathrm{kg} \mathrm{m}^{-2}\right)$ & $22.6 \pm 2.8$ & $22.5 \pm 3.3$ & 0.33 \\
\hline Estimated GFR $\left(\mathrm{ml} \mathrm{min}-1\right.$ per $\left.1.73 \mathrm{~m}^{2}\right)$ & $86.0 \pm 14.2$ & $84.2 \pm 14.6$ & 0.19 \\
\hline $\mathrm{HbA1c}(\%)$ & $5.1 \pm 0.4$ & $5.1 \pm 0.4$ & 0.71 \\
\hline Estimated $\mathrm{Na}$ excretion (mEq per day) & $220.0 \pm 59.0$ & $202.4 \pm 51.0$ & $<0.01$ \\
\hline UACR ( $\left.\mathrm{mgg}^{-1}\right)$ & $8.5 \pm 5.3$ & $7.9 \pm 4.8$ & 0.24 \\
\hline
\end{tabular}

Abbreviations: BP, blood pressure; GFR, glomerular filtration ratio; HbAlc, hemoglobin A1c; UACR, urine albumin-to-creatinine ratio.

Values are mean \pm s.d. 
levels were significantly associated with incident hypertension (odds ratio $2.35,95 \%$ confidence interval $1.28-4.46$ for UACR $5-9.9 \mathrm{mg} \mathrm{g}^{-1}$ and odds ratio $2.78,95 \%$ confidence interval $1.44-5.52$ for UACR

Table 2 Comparison of baseline characteristics between subjects with incident hypertension and normotensive subjects at follow-up survey

\begin{tabular}{|c|c|c|c|}
\hline & $\begin{array}{c}\text { Incident } \\
\text { hypertension }\end{array}$ & Normotensive & P-value \\
\hline Number of participants & 133 & 279 & \\
\hline Age (years) & $59.4 \pm 8.8$ & $55.6 \pm 8.3$ & $<0.01$ \\
\hline Men (\%) & 46.6 & 35.9 & 0.04 \\
\hline Systolic BP (mm Hg) & $127.1 \pm 9.4$ & $119.5 \pm 11.4$ & $<0.01$ \\
\hline Diastolic BP (mm Hg) & $76.7 \pm 6.9$ & $72.2 \pm 8.7$ & $<0.01$ \\
\hline Smoker (\%) & 30.8 & 27.9 & 0.54 \\
\hline Alcohol consumption (\%) & 48.1 & 39.1 & 0.08 \\
\hline Body mass index $\left(\mathrm{kg} \mathrm{m}^{-2}\right)$ & $23.0 \pm 2.8$ & $22.4 \pm 2.7$ & 0.03 \\
\hline Estimated GFR $\left(\mathrm{ml} \mathrm{min}{ }^{-1}\right.$ per $\left.1.73 \mathrm{~m}^{2}\right)$ & $86.8 \pm 14.0$ & $85.6 \pm 14.4$ & 0.22 \\
\hline $\mathrm{HbA1c}(\%)$ & $5.1 \pm 0.4$ & $5.1 \pm 0.4$ & 0.99 \\
\hline Estimated $\mathrm{Na}$ excretion (mEq per day) & $226.4 \pm 62.1$ & $217.6 \pm 57.4$ & 0.17 \\
\hline UACR $\left(\mathrm{mgg}^{-1}\right)$ & $10.1 \pm 6.5$ & $7.8 \pm 4.4$ & $<0.01$ \\
\hline
\end{tabular}

Abbreviations: BP, blood pressure; GFR, glomerular filtration ratio; HbAlc, hemoglobin Alc; UACR, urine albumin-to-creatinine ratio.

Values are mean \pm s.d.
10-29.9 vs. UACR $<5 \mathrm{mgg}^{-1}$, respectively). The multivariate model showed that the associations between the UACR level and incident hypertension remained significant after adjusting for possible confounders, including age, sex, smoking status, alcohol consumption, BMI, HbAlc and 24-h urinary excretion of sodium (Model 1; Table 3). The difference in baseline UACR levels between the subjects with and without prehypertension had marginal significance $\left(8.8 \pm 5.6\right.$ vs. $7.8 \pm 4.6 \mathrm{mg} \mathrm{gCr}^{-1}$, $P=0.09$ ). Therefore, in Model 2 we further adjusted for BP categories at baseline in addition to covariates in Model 1, and the significance between UACR and incident hypertension association was preserved.

\section{Subgroup analyses}

We performed multiple logistic regression analyses (Model 1) in subgroups divided by the following categories: age $(<60$ and $\geqslant 60$ years old), sex (men and women), smoking status (smoker and neversmoker), alcohol consumption (habitual drinker and non-habitual drinker), obesity (obesity and non-obesity), estimated urinary sodium excretion ( $<220$ and $\geqslant 220 \mathrm{mEq}$ per day) and BP categories (normal BP and prehypertension). This analysis showed that subjects with increased UACR $\left(\geqslant 5 \mathrm{mgg}^{-1}\right)$ had a higher risk for incident hypertension than those with low UACR $\left(<5 \mathrm{mgg}^{-1}\right)$ in any subgroup, and there were no significant interactions among these groups (Table 4).

Table 3 Risk factors for incident hypertension

\begin{tabular}{|c|c|c|c|c|c|}
\hline Baseline factors & & Model 1; OR $(95 \% \mathrm{Cl})$ & $\mathrm{P}$-value & Model 2; OR (95\% Cl) & P-value \\
\hline Age & per 1 year increase & $1.05(1.03-1.08)$ & $<0.01$ & $1.05(1.02-1.08)$ & $<0.01$ \\
\hline Men & vs. Women & $1.40(0.74-2.67)$ & 0.30 & $1.24(0.64-2.39)$ & 0.52 \\
\hline Smoker & vs. Non-smoker & $0.90(0.50-1.63)$ & 0.74 & $1.12(0.61-2.07)$ & 0.72 \\
\hline Alcohol consumption & vs. No alcohol consumption & $1.38(0.79-2.42)$ & 0.26 & $1.39(0.78-2.47)$ & 0.26 \\
\hline Body mass index & per $1 \mathrm{~kg} \mathrm{~m}^{-2}$ increase & $1.10(1.02-1.20)$ & 0.02 & $1.08(0.99-1.18)$ & 0.06 \\
\hline $\mathrm{HbAlc}$ & per $0.1 \%$ increase & $0.71(0.39-1.30)$ & 0.27 & $0.62(0.33-1.14)$ & 0.12 \\
\hline Estimated $\mathrm{Na}$ excretion $>220 \mathrm{mEq}$ per day & vs. $<220 \mathrm{mEq}$ per day & $0.89(0.56-1.40)$ & 0.62 & $0.88(0.55-1.40)$ & 0.58 \\
\hline UACR $5.0-9.9 \mathrm{mgg}^{-1}$ & vs. $<5 \mathrm{mgg}^{-1}$ & $2.35(1.28-4.46)$ & $<0.01$ & $2.15(1.16-4.10)$ & 0.01 \\
\hline UACR 10.0-29.9 mg g-1 & vs. $<5 \mathrm{mgg}^{-1}$ & $2.78(1.44-5.52)$ & $<0.01$ & $2.67(1.36-5.38)$ & $<0.01$ \\
\hline Prehypertension & vs. Normal BP & & & $3.54(2.00-6.55)$ & $<0.01$ \\
\hline
\end{tabular}

Abbreviations: BP, blood pressure; 95\% Cl, 95\% confidence interval; HbAlc, hemoglobin Alc; OR, odds ratio; UACR, urine albumin-to-creatinine ratio.

Table 4 Odds ratio of UACR $\geqslant 5 \mathrm{mgg}^{-1}$ (vs. UACR $<5 \mathrm{mgg}^{-1}$ ) for incident hypertension in subgroups

\begin{tabular}{|c|c|c|c|c|}
\hline Subgroup & $\mathrm{n}$ & OR $(95 \% \mathrm{Cl})$ & P-value & $\mathrm{P}$ for interaction \\
\hline Age $<60$ years & 255 & $2.49(1.20-5.51)$ & 0.01 & 0.93 \\
\hline Age $\geqslant 60$ years & 157 & $2.46(1.02-6.37)$ & 0.04 & \\
\hline Women & 250 & $1.64(0.68-4.42)$ & 0.28 & 0.63 \\
\hline Men & 162 & $2.64(1.29-5.61)$ & $<0.01$ & \\
\hline Non-smoker & 292 & $2.03(0.98-4.46)$ & 0.06 & 0.76 \\
\hline Smoker & 120 & $2.91(1.20-7.54)$ & 0.02 & \\
\hline No alcohol consumption & 239 & $3.01(1.18-8.70)$ & 0.02 & 0.22 \\
\hline Alcohol consumption & 173 & $1.78(0.85-3.84)$ & 0.13 & \\
\hline $\mathrm{BMI}<25 \mathrm{~kg} \mathrm{~m}^{-2}$ & 334 & $2.19(1.14-4.40)$ & 0.02 & 0.69 \\
\hline $\mathrm{BMI} \geqslant 25 \mathrm{~kg} \mathrm{~m}^{-2}$ & 78 & $1.93(0.61-6.64)$ & 0.27 & \\
\hline Estimated $\mathrm{Na}$ excretion $<220 \mathrm{mEq}$ per day & 225 & $1.41(0.64-3.24)$ & 0.40 & 0.13 \\
\hline Estimated $\mathrm{Na}$ excretion $\geqslant 220 \mathrm{mEq}$ per day & 187 & $3.18(1.40-7.85)$ & $<0.01$ & \\
\hline Normal BP & 123 & $0.91(0.23-3.96)$ & 0.90 & 0.28 \\
\hline Prehypertension & 289 & $2.59(1.37-5.12)$ & $<0.01$ & \\
\hline
\end{tabular}

Abbreviations: BMI, body mass index; BP; blood pressure; 95\% CI, 95\% confidence interval; OR, odds ratio; UACR, urine albumin-to-creatinine ratio. 


\section{DISCUSSION}

In this cohort study, we showed that a slight increase in urinary albumin excretion $\left(5-29.9 \mathrm{mg} \mathrm{g}^{-1}\right)$, even within the normal range, is an independent risk of incident hypertension in a community-based Japanese population. This association was preserved in subgroups divided by the subjects' backgrounds. This finding suggests that UACR measurements are useful for predicting the future development of hypertension in the general population.

Hypertension is generally recognized as a cause of albuminuria. However, our results showed that increased urinary albumin excretion within the normal range precedes hypertension. Albuminuria is a biomarker of microvascular endothelial injury and an early clinical manifestation of chronic kidney disease. ${ }^{12,13}$ Recent studies have reported a link between endothelial dysfunction, arterial stiffness and BP. ${ }^{14-17}$ Vascular endothelial dysfunction may induce an increase in $\mathrm{BP}$, and this process may be reflected as a slight increase in urinary albumin excretion. The mechanisms underlying this relationship need to be further examined.

Previous studies have reported relationships between low-grade UACR, even within the normal range $\left(5.6-15 \mathrm{mg} \mathrm{g}^{-1}\right)$, and all-cause and cardiovascular mortality, ${ }^{3,4,18}$ cardiovascular disease ${ }^{19-21}$ and atherosclerotic indicators. ${ }^{22-24}$ Although we adopted a cut-off value of UACR $5 \mathrm{mg} \mathrm{g}^{-1}$ in this analysis, this value might differ depending on the characteristics of the examined population. Further studies are required for determining the optimal cut-off value for targeting several outcomes.

Urinary albumin excretion is reported to be associated with salt intake, alcohol consumption, BMI and smoking. ${ }^{25-27}$ We analyzed these interactions in this study; however, there were no significant interactions. This result may be because of the relatively small sample size and the healthy, non-obese population of this study, in which a small but significant association could not be determined.

The rate of incident hypertension in other studies is $8.9-26.5 \%$ over 2-8 years of follow-up. ${ }^{5-9}$ Compared with these studies, the current study showed a higher rate of incident hypertension $(33.1 \%)$. This discrepancy may be partially explained by the characteristics of the examined population, which included older subjects, and the relatively longer follow-up period. However, our result was in line with the results in Western populations. Accordingly, the current study conducted in Japanese subjects confirmed the usefulness of UACR as a predictive factor for incident hypertension in a population with different background characteristics.

In the normal BP subgroup, high UACR $\left(>5 \mathrm{mggCr}^{-1}\right)$ did not show a significant increase in odds ratio for incident hypertension, unlike other groups. We speculate that this is partly due to the small number of events in this subgroup (17 incident hypertension among 123 subjects with normal BP at baseline). This point should be examined in a longer follow-up period.

The strengths of this study include the large, community-based population, standardized ascertainment of BP and credible clinical information adjusted for multiple conventional risk factors associated with hypertension. However, this study also has several potential limitations. First, we had limited statistical power to determine the presence of a linear correlation between UACR and incident hypertension. Second, we obtained only a single urine sample to measure UACR. Although UACR shows day-to-day variation, a single-void urine sample correlates well with 24-h urinary albumin excretion. ${ }^{28}$ Third, the subjects in this study constituted a self-selected population; therefore, caution is required when generalizing our findings to other populations.
In conclusion, slight increases in urine albumin excretion, even within the normal range, were associated with an increased risk of incident hypertension in this community-based Japanese population. The measurement of urinary albumin excretion might be useful as a simple and non-invasive tool for predicting incident hypertension in the general population.

\section{CONFLICT OF INTEREST}

The authors declare no conflict of interest.

\section{ACKNOWLEDGEMENTS}

This study was supported by a grant-in-aid from the 21st Century Center of Excellence (COE) and the Global COE program of the Japan Society for the Promotion of Science, and MEXT/JSPS KAKENHI grant number 25293138.

1 Lopez AD, Mathers CD, Ezzati M, Jamison DT, Murray CJL. Global and regional burden of disease and risk factors, 2001: systematic analysis of population health data. Lancet 2006; 367: 1747-1757.

2 Chobanian AV, Bakris GL, Black HR, Cushman WC, Green LA, Izzo Jr JL, Jones DW, Materson BJ, Oparil S, Wright Jr JT, Roccella EJ. The Seventh Report of the Joint National Committee on Prevention, Detection, Evaluation, and Treatment of High Blood Pressure: the JNC 7 report. JAMA 2003; 289: 2560-2572.

3 Matsushita K, van der Velde M, Astor BC, Woodward M, Levey AS, de Jong PE, Coresh J, Gansevoort RT. Association of estimated glomerular filtration rate and albuminuria with all-cause and cardiovascular mortality in general population cohorts: a collaborative meta-analysis. Lancet 2010; 375: 2073-2081.

4 Konta T, Kudo K, Sato H, Ichikawa K, Ikeda A, Suzuki K, Hirayama A, Shibata Y, Watanabe T, Daimon M, Kato T, Ueno Y, Kayama T, Kubota I. Albuminuria is an independent predictor of all-cause and cardiovascular mortality in the Japanese population: the Takahata study. Clin Exp Nephrol 2013; 17: 805-810.

5 Brantsma AH, Bakker SJ, de Zeeuw D, de Jong PE, Gansevoort RT. Urinary albumin excretion as a predictor of the development of hypertension in the general population. J Am Soc Nephrol 2006; 17: 331-335.

6 Forman JP, Fisher ND, Schopick EL, Curhan GC. Higher levels of albuminuria within the normal range predict incident hypertension. J Am Soc Nephrol 2008; 19: 1983-1988.

7 Gerber LM, Schwartz JE, Pickering TG. Albumin-to-creatinine ratio predicts change in ambulatory blood pressure in normotensive persons: a 7.5-year prospective study. Am J Hypertens 2006; 19: 220-226.

8 Jessani S, Levey AS, Chaturvedi N, Jafar TH. High normal levels of albuminuria and risk of hypertension in Indo-Asian population. Nephrol Dial Transplant 2012; 27(Suppl 3): iii58-iii64.

9 Wang TJ, Evans JC, Meigs JB, Rifai N, Fox CS, D'Agostino RB, Levy D, Vasan RS. Lowgrade albuminuria and the risks of hypertension and blood pressure progression. Circulation 2005; 111: 1370-1376.

10 Matsuo S, Imai E, Horio M, Yasuda Y, Tomita K, Nitta K, Yamagata K, Tomino Y, Yokoyama $\mathrm{H}$, Hishida A. Revised equations for estimated GFR from serum creatinine in Japan. Am J Kidney Dis 2009; 53: 982-992.

11 Kawasaki T, Itoh K, Uezono K, Sasaki H. A simple method for estimating $24 \mathrm{~h}$ urinary sodium and potassium excretion from second morning voiding urine specimen in adults. Clin Exp Pharmacol Physiol 1993; 20: 7-14.

12 Ito S, Nagasawa T, Abe M, Mori T. Strain vessel hypothesis: a viewpoint for linkage of albuminuria and cerebro-cardiovascular risk. Hypertens Res 2009; 32: 115-121.

13 Satoh M. Endothelial dysfunction as an underlying pathophysiological condition of chronic kidney disease. Clin Exp Nephrol 2012; 16: 518-521.

14 Neves MF, Kasal DA, Cunha AR, Medeiros F. Vascular dysfunction as target organ damage in animal models of hypertension. Int J Hypertens 2012; 2012: 187526.

15 Figueiredo VN, Yugar-Toledo JC, Martins LC, Martins LB, de Faria AP, de Haro Moraes C, Sierra C, Coca A, Moreno H. Vascular stiffness and endothelial dysfunction: correlations at different levels of blood pressure. Blood Press 2012; 21: 31-38.

16 Higashi Y, Kihara Y, Noma K. Endothelial dysfunction and hypertension in aging. Hypertens Res 2012; 35: 1039-1047.

17 Schulz E, Gori T, Munzel T. Oxidative stress and endothelial dysfunction in hypertension. Hypertens Res 2011; 34: 665-673.

18 Kovesdy CP, Lott EH, Lu JL, Malakauskas SM, Ma JZ, Molnar MZ, Kalantar-Zedeh K. Outcomes associated with microalbuminuria: effect modification by chronic kidney disease. J Am Coll Cardiol 2013; 61: 1626-1633.

19 Xu J, Knowler WC, Devereux RB, Yeh J, Umans JG, Begum M, Febsitz RR, Lee ET. Albuminuria within the 'normal' range and risk of cardiovascular disease and death in American Indians: the Strong Heart Study. Am J Kidney Dis 2007; 49: 208-216.

20 Arnlov J, Evans JC, Meigs JB, Wang TJ, Fox CS, Levy D, Benjamin EJ, D'Agostino RB, Vasan RS. Low-grade albuminuria and incidence of cardiovascular disease events in nonhypertensive and nondiabetic individuals: the Framingham Heart Study. Circulation 2005; 112: 969-975. 
21 Blecker S, Matsushita K, Kottgen A, Loehr LR, Bertoni AG, Boulware LE, Coresh J. High-normal albuminuria and risk of heart failure in the community. Am J Kidney Dis 2011; 58: 47-55.

22 Kim BJ, Lee HA, Kim NH, Kim MW, Kim BS, Kang JH. The association of albuminuria, arterial stiffness, and blood pressure status in nondiabetic, nonhypertensive individuals. J Hypertens 2011; 29: 2091-2098.

23 Lieb W, Mayer B, Stritzke J, Doering A, Hense HW, Loewel H, Erdmann J, Schunkert H. Association of low-grade urinary albumin excretion with left ventricular hypertrophy in the general population: the MONICA/KORA Augsburg Echocardiographic Substudy. Nephrol Dial Transplant 2006; 21: 2780-2787.

$24 \mathrm{Ma} \mathrm{H}$, Lin H, Hofman A, Hu Y, Li X, He W, Jeekel J, Jin X, Gao J, Zhao N, Gao X. Lowgrade albuminuria is associated with carotid atherosclerosis in normotensive and euglycemic Chinese middle-aged and elderly adults: The Shanghai Changfeng Study Atherosclerosis 2013; 228: 237-242.

25 Nagasawa Y, Yamamoto R, Rakugi H, Isaka Y. Cigarette smoking and chronic kidney diseases. Hypertens Res 2012; 35: 261-265.

26 Konta T, Hao Z, Abiko H, Ishikawa M, Takahashi T, Ikeda A, Ichikawa K, Takasaki S Kubota I. Prevalence and risk factor analysis of microalbuminuria in Japanese general population: the Takahata study. Kidney Int 2006; 70: 751-756.

27 White SL, Polkinghorne KR, Cass A, Shaw JE, Atkins RC, Chadban SJ. Alcoho consumption and 5-year onset of chronic kidney disease: the AusDiab study. Nephrol Dial Transplant 2009; 24: 2464-2472.

28 Nathan DM, Rosenbaum C, Protasowicki VD. Single-void urine samples can be used to estimate quantitative microalbuminuria. Diabetes Care 1987; 10: 414-418. 